LA-UR- $95-4148$

TITLE:

AUTHORS:

SUBMITTED TO:

\section{CARBON, NITROGEN, AND OXYGEN ION IMPLANTATION OF STAINLESS STEEL}

D. J. REJ, N. V. GAVRILOV, D. EMLIN, I. HENINS, K. KERN, T. KURENNYKH, V. N. MIZGULIN, C. P. MUNSON, M. NASTASI, J. T. SCHEUER, V. WYKHODETS, K. C. WALTER

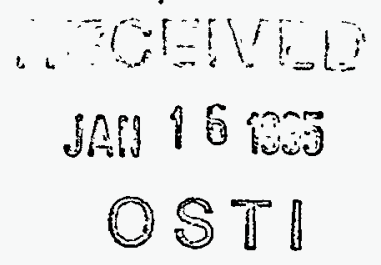

1995 Fall Meeting of the Materials Research Society Symposium A: Ion-Solid Interactions Boston, MA

November 27-December 1, 1995

\title{
DISCLAIMER
}

This report was prepared as an account of work sponsored by an agency of the United States Government. Neither the United States Government nor any agency thereof, nor any of their employees, makes any warranty, express or implied, or assumes any legal liability or responsibility for the accuracy, completeness, or usefulness of any information, apparatus, product, or process disclosed, or represents that its use would not infringe privately owned rights. Reference herein to any specific commercial product, process, or service by trade name, trademark, manufacturer, or otherwise does not necessarily constitute or imply its endorsement, recommendation, or favoring by the United States Government or any agency thereof. The views and opinions of authors expressed herein do not necessarily state or reflect those of the United States Government or any agency thereof.

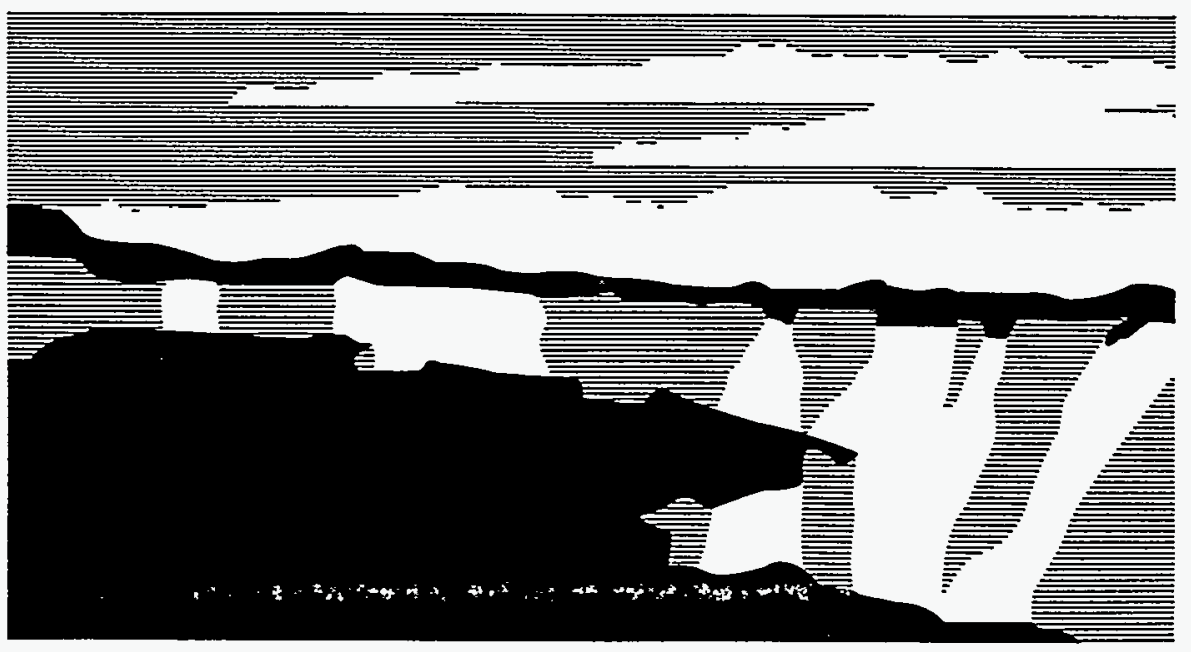

Los Alamos, National Laboratory, an attirmative action/equal opportunity employer, is operated by the University of California for the U.S. Department of Energy under contract W-7405-ENG-36. By acceptance of this article, the publisher recognizes that the U.S. Government retains a nonexclusive, royalty-free license to publish or reproduce the published form of this contribution, or to allow others to do so, for U.S. Govermment purposes. The Los Alamos National Laboratory requests that the publisher identify this article as work performed under the auspices of the U.S. Department of Energy. 


\section{CARBON, NITROGEN, AND OXYGEN ION IMPLANTATION OF STAINLESS STEEL}

\section{D.J. REJ ${ }^{1}$, N.V. GAVRILOV ${ }^{2}$, D. EMLIN ${ }^{2}$, I. HENINS ${ }^{1}$, K. KERN ${ }^{3}$, T. KURENNYKH ${ }^{4}$, V.N. MIZGULIN ${ }^{2}$, C.P. MUNSON ${ }^{1}$, M.NASTASI $^{1}$, J.T. SCHEUER ${ }^{1}$, V. VYKHODETS ${ }^{4}$, K. C. WALTER ${ }^{1}$}

${ }^{1}$ Los Alamos National Laboratory, MS-D434, Los Alamos, NM 87545, drej@lanl.gov

${ }^{2}$ Inst. of Electrophysics, 34 Komsomolskaya St., Ekaterinburg 620049, Russia, pulsar@ief.intec.ru

${ }^{3}$ Center for Materials Research, Norfolk State Univ., Norfolk, VA 23401

${ }^{4}$ Inst. of Metal Physics, 18 Kovalevskaya St., Ekaterinburg 620219, Russia

\section{ABSTRACT}

Ion implantation experiments of $\mathrm{C}, \mathrm{N}$ and $\mathrm{O}$ into stainless steel have been performed, with beam-line and plasma source ion implantation methods. Acceleration voltages are varied between 27 and $50 \mathrm{kV}$, with pulsed ion current densities between 1 and $10 \mathrm{~mA} / \mathrm{cm}^{2}$. Implanted doses range from 0.5 to $3 \times 10^{18} \mathrm{~cm}^{-2}$, while workpiece temperatures are maintained between 25 and $800^{\circ} \mathrm{C}$. The implant concentration profiles, microstructure and surface mechanical properties of the implanted materials are reported.

\section{INTRODUCTION}

Ion implantation of light elements has proven to be an effective technique to improve the tribological properties of metals. Stainless steel is a particularly interesting material to study since many of the constituent atoms such as chromium readily form covalently bonded compounds with the implanted ions, resulting in increased surface hardness, reduced friction, and altered microstructure. [1-5] In addition, implantation at elevated temperature often results in deeper modified surface layers which exceed the ballistic range of the implanted ions by an order of magnitude or more. Nitrogen implantation into stainless steel at elevated temperature is a hybrid implantation-nitriding process which results in a nitrogen-enriched outer surface with increased hardness due to higher $N$ concentrations $(20-30 \%$ at) in solid solution when compared with traditional ion and gas nitriding. [1-2] Carbon implantation is of interest since it readily forms carbides with iron which are often amorphous when there is a sufficient implant dose. [4,5] There is little data published on carbon implants at elevated temperature, and on oxygen implantation of stainless steel. In this paper we report preliminary experimental results to study the effect of $\mathrm{C}, \mathrm{N}$, and $\mathrm{O}$ implantation into stainless steel. Both beam implantation and plasma source ion implantation methods have been used.

\section{EXPERIMENT}

Implantation experiments were performed on two devices, a high-current-density, pulsed beam-line ion implanter at the Institute of Electrophysics (IEP) [6], and a plasma source ion implantation device (PSI) at Los Alamos National Laboratory (LANL) [7]. Neither apparatus utilized mass analysis or selection of the implanted ions. The IEP implanter used a magnetically-confined, hollow-cathode glow discharge ion source, created from a $\mathrm{C}_{3} \mathrm{H}_{8}, \mathrm{~N}_{2}$, or $\mathrm{O}_{2}$ background gas. Ions were accelerated to $30 \mathrm{keV}$ and extracted at current densities between 1 and $10 \mathrm{~mA} / \mathrm{cm}^{2}$ over $1 \mathrm{~ms}$ pulses at a repetition rate between 0 and $50 \mathrm{~Hz}$. Base pressures of order $10^{-5}$ torr were obtained with an oil diffusion pump. During implantation, a pressure of 3 to $6 \times 10^{-4}$ torr was measured near the workpiece (located $0.20 \mathrm{~m}$ from the accelerator grids) 
due to diffusion of gas from the ion source. High temperature implants were achieved by employing the ion beam itself to heat the workpiece.

The LANL device was operated at $27-50 \mathrm{kV}, j=1-4 \mathrm{~mA} / \mathrm{cm}^{2}$ at the workpiece over a $20-\mu \mathrm{s}$ pulsewidth and $500-2000 \mathrm{~Hz}$ pulse repetition rate. Workpiece temperatures were controlled by adjusting the repetition rate. Gas sources included $\mathrm{N}_{2}, \mathrm{NH}_{3}$, or $\mathrm{CH}_{4}$ introduced at $3-5 \times 10^{-4}$ torr. Plasmas were created with a $500-900 \mathrm{~W}, 13.56 \mathrm{MHz}$, capacitively-coupled rf source.

Workpieces consisted of cold-rolled stainless steel coupons, type 12Kh18N10T (comparable to AISI 321), composed of $0.12 \%$ (wt) C, $18 \% \mathrm{Cr}, 10 \% \mathrm{Ni}, 0.7 \% \mathrm{Ti}, 1-2 \% \mathrm{Mn}$. They were polished with diamond paste to a surface roughness of $150 \mathrm{~nm}$ or less. X-ray diffraction (XRD) of unimplanted samples revealed primarily a FCC $\gamma$ phase with lattice parameter of $0.359 \mathrm{~nm}$, with relatively small concentrations $(<3 \%)$ of $\alpha$ phase. Implanted doses ranged between 0.5 to $3 \times 10^{18} \mathrm{~cm}^{-2}$. Workpiece temperatures were maintained between 25 and $800^{\circ} \mathrm{C}$.

The composition and microstructure of the implanted materials were examined with $\mathrm{XRD}$, Rutherford backscattering (RBS), and nuclear reaction analyses (NRA) of the ${ }^{12} \mathrm{C}(\mathrm{d}, \mathrm{p})^{13} \mathrm{C}$, ${ }^{14} \mathrm{~N}(\mathrm{~d}, \alpha){ }^{12} \mathrm{C}$, and ${ }^{16} \mathrm{O}(\mathrm{d}, \mathrm{p}){ }^{17} \mathrm{O}$ reactions with a $0.9-\mathrm{MeV}$ deuteron beam, and with a $8.9 \mathrm{MeV}$ alpha particle beam. Depth profiles of the implanted nitrogen were calculated after comparing the measured NRA spectrum with that produced by a $\mathrm{TiN}_{0.82}$ reference specimen. X-ray photoelectron spectroscopy (XPS) was also used to infer depth profiles. Carbon and oxygen profiles were similarly determined with $\mathrm{U} 8$ steel and $\mathrm{Ta}_{2} \mathrm{O}_{5}$ reference materials, respectively. Vickers microhardness was measured at both 50 and $200 \mathrm{~g}$ loads, with indent depths ranging between a few tenths to several microns, depending on microhardness. More sensitive surface nanohardness and modulus measurements at depths between 20 to $800 \mathrm{~nm}$ from the surface were made with a Nano-Indenter ${ }^{\circledR}$ II [8]. Wear properties were investigated with pin-on-disk test with a 6-mm diameter ruby pin, a sliding speed of $0.94 \mathrm{~m} / \mathrm{min}$, a wear track diameter of $3 \mathrm{~mm}$, and in a $10 \%$ relative humidity atmosphere. Samples were tested with a load of $27 \mathrm{~g}$ and contact stress of $533 \mathrm{MPa}$. The yield strength of the untreated stainless steel is $200 \mathrm{MPa}$, so the conditions chosen resulted in highly accelerated wear.

\section{RESULTS}

Implant distribution profiles as determined from RBS and NRA are plotted in Figs. 1 and 2. At elevated temperatures, relatively deep penetration (when compared to the $<100 \mathrm{~nm}$ ballistic ion range) of the $\mathrm{C}$ and $\mathrm{N}$ are observed. A dramatic change in the $\mathrm{C}$ profile is observed between $\mathrm{T}=390^{\circ} \mathrm{C}$ and $480^{\circ} \mathrm{C}$. Examination of $\mathrm{N}$ profiles obtained with the same implanted dose $\left(1 \times 10^{18} \mathrm{~cm}^{-2}\right)$ but with pulse ion current densities of 3 and $10 \mathrm{~mA} / \mathrm{cm}^{2}$ reveal different spectra (Fig. 1). A lower concentration of $N$ is observed at $10 \mathrm{~mA} / \mathrm{cm}^{2}$ which was implanted at $765^{\circ} \mathrm{C}$, when compared with the $3 \mathrm{~mA} / \mathrm{cm}^{2}$ implant which was performed at $613^{\circ} \mathrm{C}$. These results suggest an increased diffusion coefficient for the $10 \mathrm{~mA} / \mathrm{cm}^{2}$ case, which may be attributed to the increased temperature and/or radiation induced phenomena associated with the high current density. [2]

An RBS spectrum of a nitrogen PSII implant dose of $1 \times 10^{18} \mathrm{~cm}^{-2}$ at $325^{\circ} \mathrm{C}$ for 1.25 hours is shown in Fig. 2. The spectrum indicates the presence of approximately $1 \times 10^{17}$ atom-cm $\mathrm{cm}^{-2}$ oxygen on the surface which is probably due to surface oxidation during the high temperature implant. No evidence of oxygen implantation was detected. The retained nitrogen dose is $5.9 \times 10^{17} \mathrm{~cm}^{-2}$ with a profile extending to a depth of about $540 \mathrm{~nm}$. The profile depth exceeds the ion range at $40 \mathrm{keV}$, which is about $60 \mathrm{~nm}$, and confirms the positive effect often observed with high temperature implantation for a PSII process. [1,3] 
Depending on temperature, the carbon implant profiles extend several microns into the samples, well beyond the ballistic range, and appear to be deeper than the nitrogen implants performed at similar temperatures. XPS analyses of ceramic coupons placed near the workpiece reveal a thin deposited carbon layer atop the implant that is graphitic with an approximately $15 \%$ concentration of the diamondlike carbon phase.

Oxygen implants show no evidence of diffusion, but rather, are confined to a near surface of order. $100 \mathrm{~nm}$ thick, comparable to the ion range. For a $1 \times 10^{18} \mathrm{~cm}^{-2}$ oxygen implant, the retained dose increases from $0.19 \times 10^{18} \mathrm{~cm}^{-2}$ at $\mathrm{T}=$ $377^{\circ} \mathrm{C}$ to $0.45 \times 10^{18} \mathrm{~cm}^{-2}$ at $710^{\circ} \mathrm{C}$, presumably because of increased surface oxidation at the higher $\mathrm{T}$.

XRD indicates that an interstitial solid solution is formed. A lattice parameter of the FCC structure changes from an initial value of $0.359 \mathrm{~nm}$ to $0.367 \mathrm{~nm}$ with $\mathrm{C} \mathrm{im}$ plantation. A transformation from $\gamma$ to $\alpha$ phase is observed, accompanied by the appearance of BCC (ferrite) and tetragonal (martensite) structures (Fig. 3), depending on temperatures. The $\mathbf{N}$ concentration are close to their maximum values for a solid solution of $\mathrm{N}$ in $\boldsymbol{\gamma}$-Fe.

Vickers hardness $\mathrm{H}_{\mathrm{v}}$ data for the beam-line implants are shown in Fig. 4. These measurements represent indent depths of order $1 \mu \mathrm{m}$. For the virgin samples, the 20 and $200 \mathrm{~g}$ loads resulted in indent depths $\delta$ of 0.7 and $7 \mu \mathrm{m}$, respectively, corresponding to a microhardness of about $200 \mathrm{~kg} / \mathrm{mm}^{2}$.
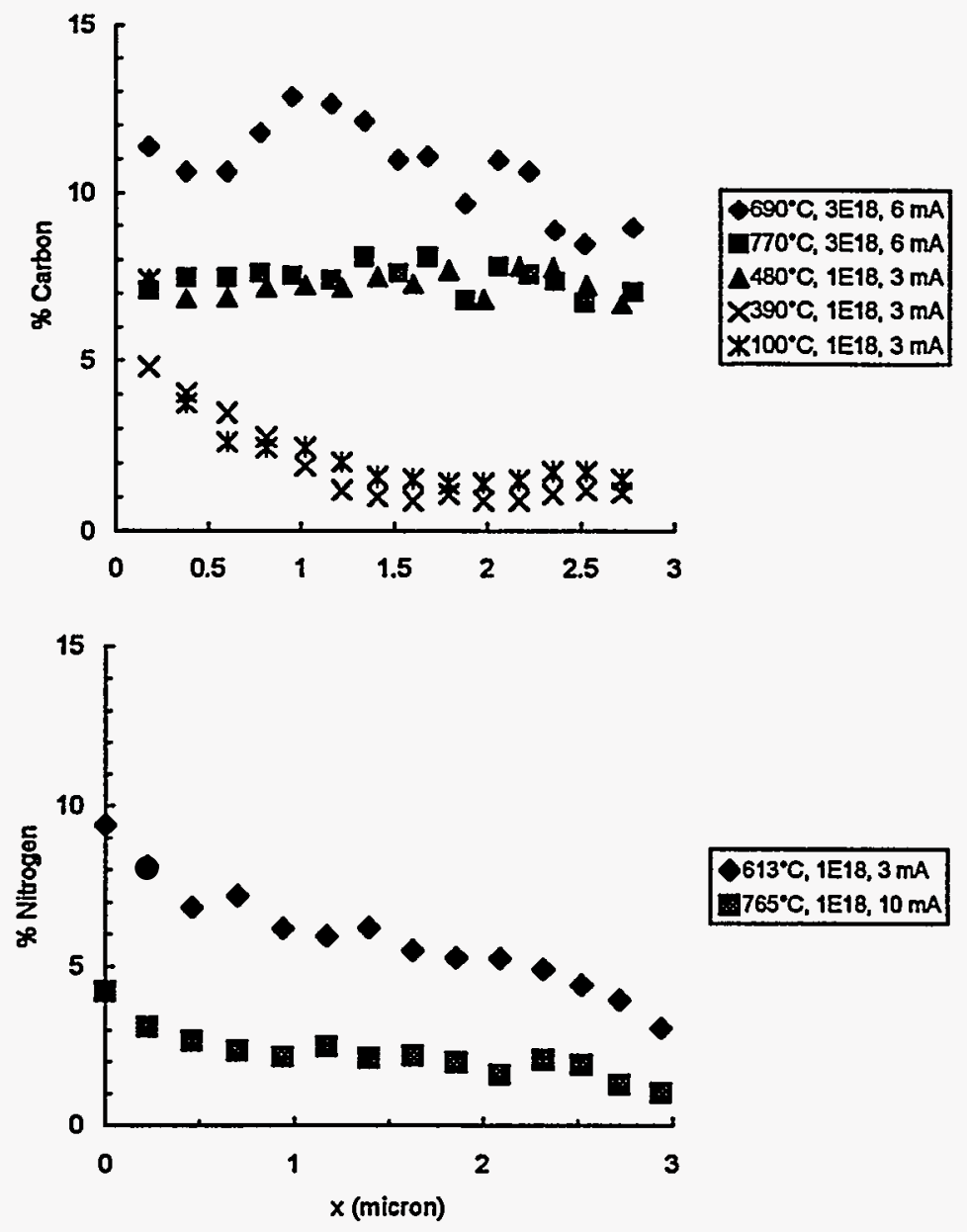

Fig. 1: Implant concentration profiles of beamline implants determined by NRA.

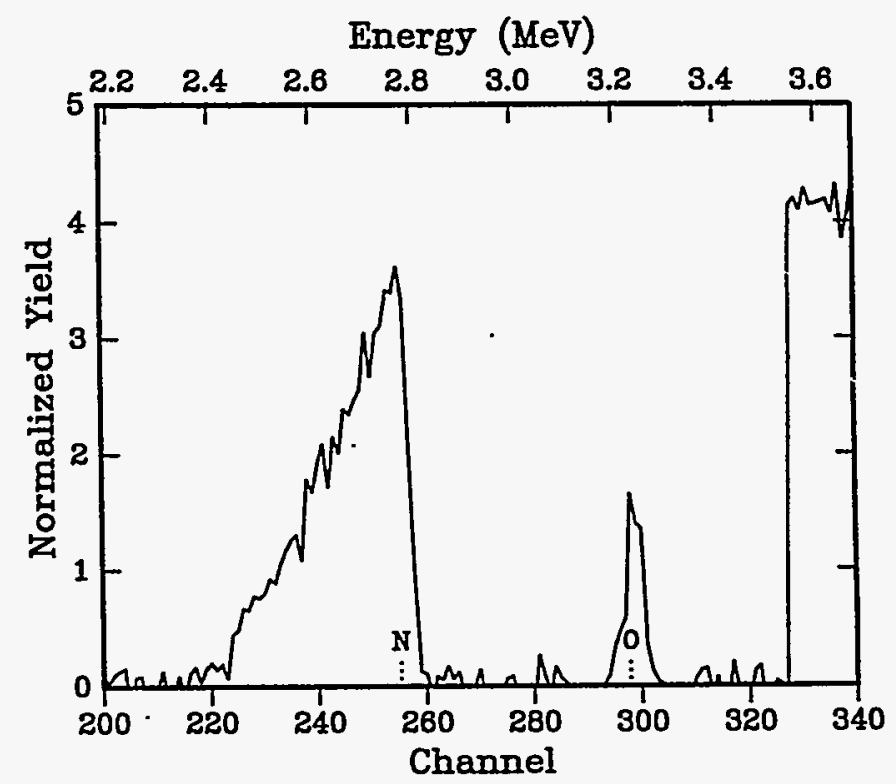

Fig. 2: RBS profile of a PSII nitrogen implant at $325^{\circ} \mathrm{C}$. 
For hardened surfaces of 1500 $\mathrm{kg} / \mathrm{mm}^{2}, \delta$ was $0.5 \mu \mathrm{m}$ at $100 \mathrm{~g}$. For low temperature carbon implants, $\mathrm{T}<400^{\circ} \mathrm{C}$, there was no measurable change in $\mathrm{H}_{\mathrm{v}}$. As $\mathrm{T}$ was increased from $400^{\circ}$ to $600^{\circ} \mathrm{C}$, one observed an approximate doubling of $H_{v}$. The highest $H_{v}$ were obtained at $\mathrm{C}_{3} \mathrm{H}_{8}$ implant doses of $3 \times 10^{18} \mathrm{~cm}^{-2}$ and intermediate temperatures. There was no clear correlation in $\mathrm{H}_{\mathrm{v}}$ with $\mathrm{C}$ ion current density the observed changes in phase microstructure, although the highest $\mathrm{H}_{\mathrm{v}}$ was observed when there was an interstitial solid solution of carbon without precipitates (i.e., when the $\gamma \rightarrow \alpha$ transformation did not occur). Changes in $\mathrm{H}_{\mathrm{v}}$ due to the heat treatment were examined by indenting the back (untreated) sides of the implanted samples and found to be less than $10 \% . \mathrm{H}_{\mathrm{v}}$ of the $\mathrm{N}$ implants also increased with $\mathrm{T}$ to approximately a factor of two. At the highest temperatures, $\mathrm{T}>$ $750^{\circ} \mathrm{C}, \mathrm{H}_{\mathrm{v}}$ decreased. In contrast to the $\mathrm{C}$ and $\mathrm{N}$ implants, oxygen implantation resulted in no discernible change in $\mathrm{H}_{\mathrm{v}}$.

The Vickers hardness measurements were confirmed with nanoindentation (Fig. 5). The nanohardness $H_{n}$ of unimplanted sample is found to be approximately $4 \mathrm{GPa}$, with a 100-nm-thick, 8-GPa outer layer, presumably due to a surface oxide. Significant increases in $\mathrm{H}_{\mathrm{n}}$ at low temperatures, $\mathrm{T}<400^{\circ} \mathrm{C}$, which could not be detected in the Vickers tests because of the deep indents, are evident for both the carbon and nitrogen implants, with little change in the modulus, indicative of an increase in surface toughness. At relatively low temperatures, the carbon implanted samples may show a small increase in $\mathrm{H}_{n}$ of about $10 \%$ over a $50-100 \mathrm{~nm}$ surface layer. Substantial hardening is evident at $\mathrm{T}=375^{\circ} \mathrm{C}$, with $\mathrm{H}_{\mathrm{n}}$ values of $13 \mathrm{GPa}$, again extending over a shallow surface
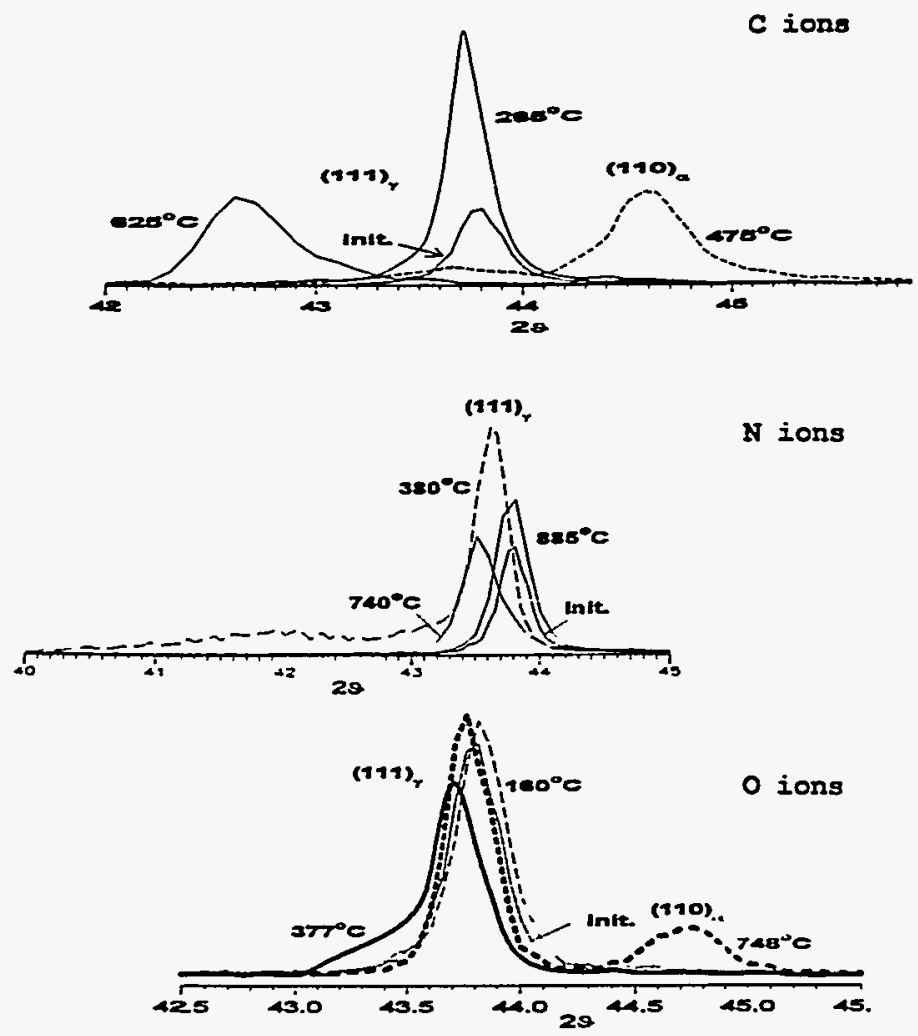

Fig. 3: X-Ray diffraction (XRD) spectra.

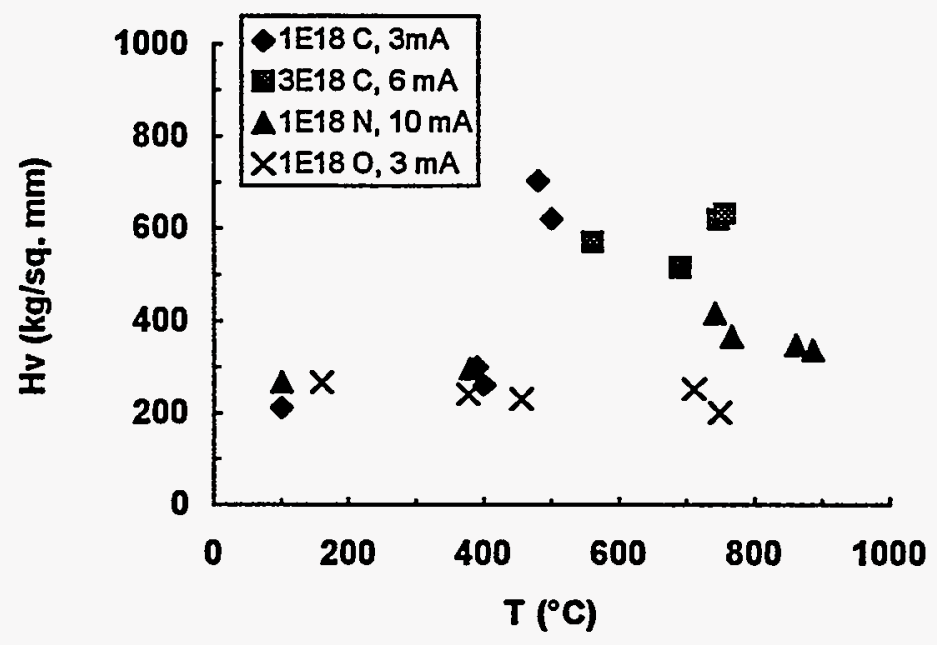

Fig. 4: Vickers hardness $H_{v}$ data obtained at $20 \mathrm{~g}$ load for $\mathrm{C}, \mathrm{N}$, and $\mathrm{O}$ implantation at a variety of pulsed ion current densities and substrate temperatures. 
layer. Substantially deeper cases are observed starting at $\mathrm{T} \approx 500^{\circ} \mathrm{C}$, which is sometime accompanied by a soft outer skin ( $\leq 400 \mathrm{~nm}$ ), possibly corresponding to the aforementioned graphitic surface film that occurs during the $\mathrm{C}$ implants. At the highest temperatures, however, of $770^{\circ} \mathrm{C}$ or greater, a more modest increase in $\mathrm{H}_{\mathrm{n}}$ over a deeper case is observed. For nitrogen implants at $\mathrm{T} \approx 100^{\circ} \mathrm{C}$, a modest increase in $\mathrm{H}_{\mathrm{n}}$ of about $10 \%$ is observed over a relatively shallow case of less than $100 \mathrm{~nm}$. The highest $\mathrm{H}_{\mathrm{n}}$ of $16 \mathrm{GPa}$ is observed at the intermediate temperature $\mathrm{T} \approx 400{ }^{\circ} \mathrm{C}$, over a somewhat deeper case depth, indicative of a modest level of diffusion induced by the elevated temperature. At the highest temperatures, $\mathrm{T}=670-860^{\circ} \mathrm{C}$, up to $3 x$ increases in $H_{n}$ is observed over a $1 \mu \mathrm{m}$ depth or more, consistent with the Vickers measurements.

Virtually no changes in $\mathrm{H}_{\mathrm{n}}$ were detected in the oxygen-implanted samples (Fig. 5). Within $100-200 \mathrm{~nm}$ from the surface, $\mathrm{H}_{\mathrm{n}}$ decreases from about $8 \mathrm{GPa}$ to $4 \mathrm{GPa}$ similar to the virgin sample, and again indicative of a surface oxide. The hard surface layer does not extend into the sample at the elevated temperatures, consistent with the NRA data. A slight increase over the outer $100 \mathrm{~nm}$ might be discernible at $\mathrm{T}=455^{\circ} \mathrm{C}$. The hardened outer layer disappears at the highest temperatures accompanied by a $2 \times$ decrease in modulus.

The pin-on-disk wear test data for the $1 \times 10^{18} \mathrm{~cm}^{-2}$-implanted-nitrogen-dose samples are plotted in Fig. 6. The wear rate for unimplanted steel was $31 \pm 9 \times 10^{-6} \mathrm{~mm}^{3} / \mathrm{N}-\mathrm{m}$. The implants performed at 100 and $860^{\circ} \mathrm{C}$ had wear rates that were $40 \%$ of that of the unimplanted material. The $\mathrm{T}=380^{\circ} \mathrm{C}$ implant had the lowest wear rate, two orders of magnitude smaller than the unimplanted material, consistent with the highest $H_{n}$ data in Fig. 5. Wear testing was terminated when the implanted zone had worn through, so the quoted wear rates represent the wear resistance of the implanted zone. Wear tests of the $\mathrm{T}=380^{\circ} \mathrm{C}$ implanted sample with the $81 \mathrm{~g}$ load resulted in rapid wear through of the implanted region. Optical microscopy of the wear tracks indicated a predominately abrasive wear mechanism for all samples.

\section{CONCLUSIONS}

Ion implantation experiments were performed with $\mathrm{C}, \mathrm{N}$, and $\mathrm{O}$ ions implanted into stainless steel over a wide range of temperatures, current densities, using both beam line and plasma source ion implantation techniques. Significant increases in the surface hardness were observed in only the nitrogen and carbon implants. Highest increases occurred at intermediate temperatures of 400 to $500^{\circ} \mathrm{C}$, with case depths of 5 to 10 times the ballistic ranges. Improvements in wear up to $100 \times$ were observed. Deeper penetration of both $\mathrm{C}$ and $\mathrm{N}$ were found at higher temperatures, but with reduced improvement in surface hardness. In contrast, elevated temperatures did not increase the implanted oxygen depth. Moreover, oxygen implantation at any temperature did not lead to improved hardness. A more detailed account of these experiments will soon follow in a journal manuscript.

\section{ACKNOWLEDGMENTS}

The authors are grateful for able technical support provided by J. Garcia, D. Roybal, B. Vigil, and by N. Baker and B. Lucas of Nanoinstruments Corp. This research is supported by the U.S. Dept. of Energy (DOE) and State Dept., and DOE Grant DE-FG0194EW11493. 
Carbon

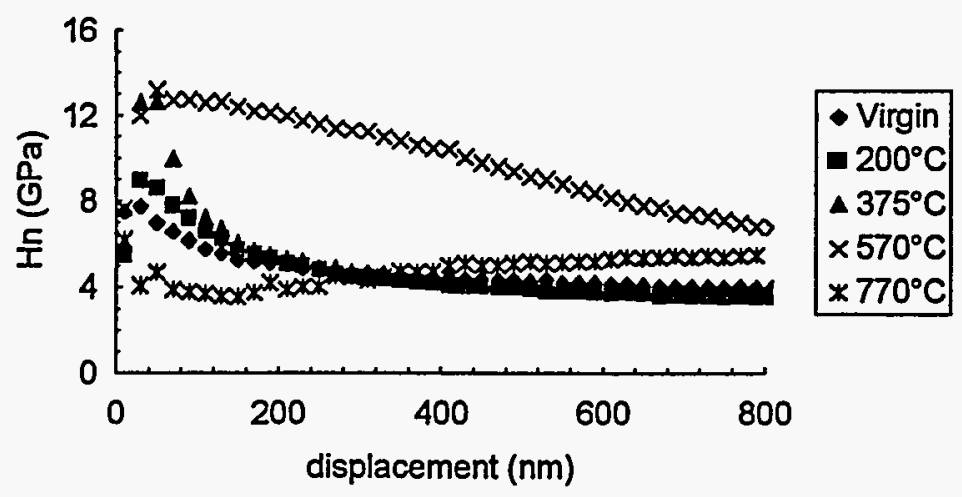

Nitrogen

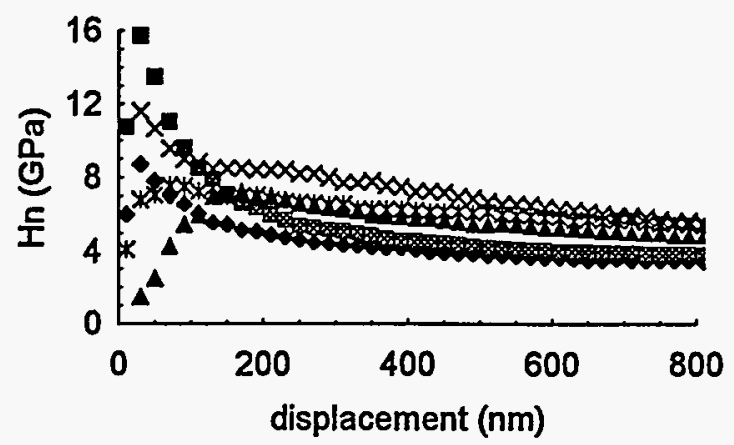

Oxygen

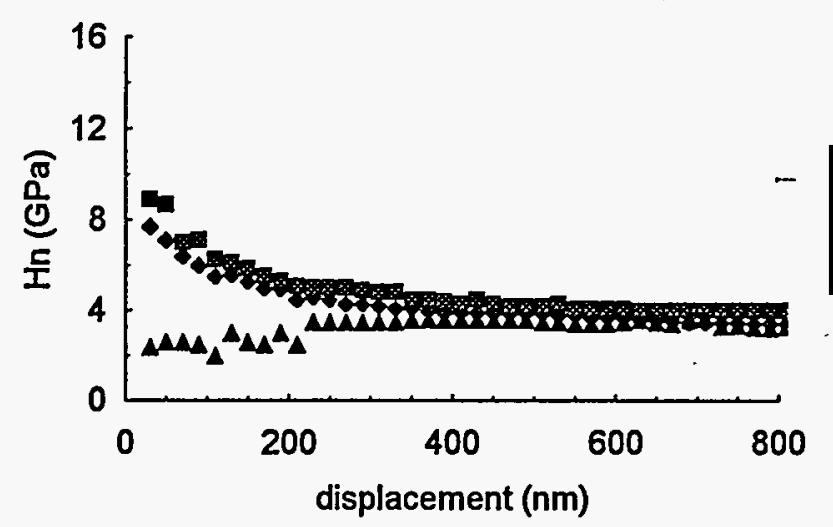

Fig. 5: Nanohardness $H_{n}$ for $C, N$, and $O$ implants performed at a variety of temperatures.

\section{REFERENCES}

[1] R. Wei, J. Vajo, J. Matossian, P. Wilbur, J. Davis, D. Williamson, G. Collins, Surf. Coat. and Technol. (in press).

[2] R. Wei, B. Shogrin, P. Wilbur, O. Ozturk, D. Williamson, I. Ivanov, E. Metin, Trans. ASME 116, 870 (1994).

[3] M. Samandi, B. Shedden, D. Smith, G. Collins, R. Hutchings, J. Tendys, Surf. Coat. Technol. 59, 261 (1993).

[4] J. Chen, J. Blanchard, J. R. Conrad, R.A. Dodd et al., Surf. Coatings and Tech. 53, 267-275 (1992)

[5] D. Follstaedt et al., J. Appl. Phys. 66, 2743 (1989).

[6] N. Gavrilov, N.Mizgulin, V. Nikulin, S. Pnomarev, Proc. $10^{\text {th }}$ Int. Conf. on High Power Particle Beams, p.435 (Maxwell Labs, San Diego, 1994).

[7] B. Wood, I. Henins, W. Reass, D. Rej, H. Davis, R. Muenchausen, G. Johnston, H. Schmidt, Nucl. Instr. Meth. B96, 429 (1995).

[8] W. C. Oliver, Mat. Res. Soc. Bulletin 11, 15 (1986).

Fig. 6: Pin-on-disk wear rates of the beamline nitrogen implanted samples.

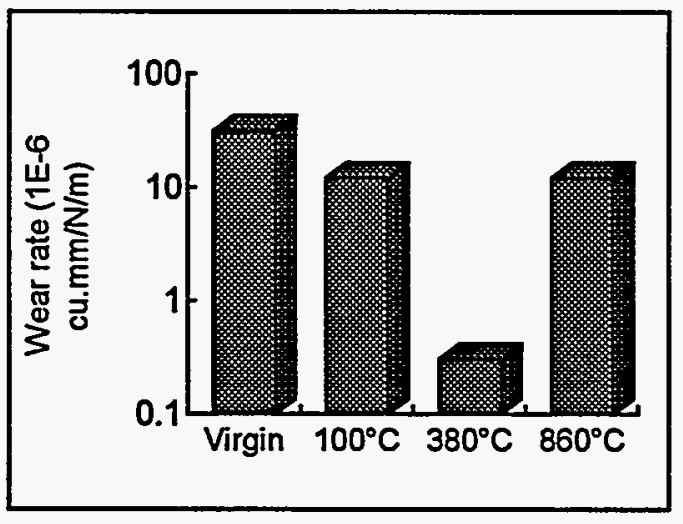

